\title{
LEITURA DELEITE COMO PRÁTICA FORMADORA: REFLEXÕES A PARTIR DA EXPERIÊNCIA DO PNAIC/UNICAMP (2013-2014)
}

\author{
Ana Lúcia Guedes-Pinto ${ }^{1}$ \\ Adriana Missae Momma-Bardela ${ }^{2}$
}

\section{Resumo}

Neste artigo, temos como objetivo focalizar alguns dos sentidos construídos pelas professoras alfabetizadoras sobre a leitura deleite como uma atividade permanente da rotina das práticas pedagógicas desenvolvidas em encontros de formação continuada de professores. A partir de seus dizeres a respeito de como compreenderam esses momentos, procuramos destacar essa abordagem como uma das formas de se trabalhar a dimensão da leitura (dentro de uma proposta alfabetizadora) em que o sujeito é tomado como alguém que se posiciona frente àquilo que lê e vivencia nas práticas formadoras. Para desenvolver nossa reflexão nos baseamos nos resultados da pesquisa intitulada "Formação, Alfabetização e Letramento: a experiência do Pacto Nacional pela Alfabetização na Idade Certa no contexto do estado de São Paulo" (Processo nº08692/2013-8 CNPq). Analisamos alguns fragmentos de entrevistas realizadas com as Professoras Alfabetizadoras (PA) de municípios do estado de São Paulo. A metodologia da pesquisa baseia-se na abordagem qualitativo interpretativa e seguiu os pressupostos da História Oral. Os dizeres das PA apresentam pistas que nos indicam as potências de um trabalho de formação que toma como base a vivência de alguns de seus princípios como forma de que tais vivências possam ser multiplicadas.

Palavras-chave: Formação continuada de professores. Práticas de leitura. Leitura e formação.

\section{PLEASURE READING AS DEVELOPMENT PRACTICE: REFLECTIONS FROM THE EXPERIENCE OF PNAIC / UNICAMP (2013-2014)}

\begin{abstract}
In this article, we aim to focus some of the meanings attributed by literacy teachers to a activity known as pleasure reading, a routine pedagogical practice developed in

${ }^{1}$ Professora Titular da Faculdade de Educação/UNICAMP. Doutora em Linguística Aplicada pelo IEL/UNICAMP. Vinculada, como Coordenadora Geral na UNICAMP, em 2013 e 2014, ao Pacto Nacional pela Alfabetização na Idade Certa - PNAIC. https://orcid.org/0000-0002-0857-8187

2 Professora da Faculdade de Educação/UNICAMP. Doutora em Educação pela FE/UNICAMP. Vinculada, como Coordenadora Adjunta na UNICAMP, em 2013 e 2014, ao Pacto Nacional Pela Alfabetização na Idade Certa (PNAIC). https://orcid.org/0000-0002-2927-5599
\end{abstract}


continuing teacher education encounters and courses. From the teachers' comments about how they understood these moments, we try to highlight this approach as one of the ways of working the dimension of reading (within a basic literacy proposal) in which the reader is understood as someone who takes a stance as about what he reads and what formative practices are worth experiencing. Our reflection is based on the results of a research project entitled "Formação, Alfabetização e Letramento: a experiência do Pacto Nacional pela Alfabetização na Idade Certa no contexto do estado de São Paulo" (Case No. 408692 / 2013-8 CNPq). We analyzed some fragments of interviews conducted with Basic Literacy teachers of several municipalities in the state of São Paulo. Our research approach is qualitative and interpretive, and adopts some of the assumptions of Oral History. The literacy teachers narratives present clues that indicate the potential of teacher formation that takes as its basis experience and devises ways that these experiences can be multiplied.

Keywords: Continuing teacher development. Reading practices. Reading and formation.

\section{LECTURA PLACER COMO PRÁCTICA FORMADORA: REFLEXIONES A PARTIR DE LA EXPERIENCIA DEL PNAIC / UNICAMP (2013-2014)}

\section{Resumen}

En este artículo, tenemos como objetivo focalizar algunos de los sentidos construidos por las profesoras alfabetizadoras sobre la lectura deleite como una actividad permanente de la rutina de prácticas pedagógicas desarrolladas en encuentros de formación continuada de profesores. A partir de sus palabras acerca de cómo comprendieron estos momentos, procuramos destacar este enfoque como una de las formas de trabajar la dimensión de la lectura (dentro de una propuesta alfabetizadora) en que el sujeto es tomado como alguien que se posiciona frente a lo que lee y experimenta en las prácticas formadoras. Para desarrollar nuestra reflexión nos basamos en los resultados de la investigación titulada "Formação, Alfabetização e Letramento: a experiência do Pacto Nacional pela Alfabetização na Idade Certa no contexto do estado de São Paulo" (Proceso nº 408692 / 2013-8 CNPq). Analizamos algunos fragmentos de entrevistas realizadas con las Profesoras Alfabetizadoras (PA) de municipios del estado de São Paulo. La metodología de la investigación se basa en el enfoque cualitativo interpretativo y sigue los presupuestos de la Historia Oral. Las hablas de la PA presentan pistas del potencial de un trabajo de formación que toma como base la vivencia de algunos de sus principios como mecanismo para tales vivencias puedan ser multiplicadas.

Palabras clave: Formación continuada de profesores. Prácticas de lectura. Lectura y formación. 
É apenas por ocasião do ato de ler, isto é, quando a linguagem confiada a letras, espaços e sinais de pontuação volta à vida através do olhar humano, que escrita e fala evidenciam o pacto que as entrelaça. Quando surgem novas escritas, parece que essa trama se torna mais misteriosa e, por isso, mais instigante. Mudando de pele, a escrita desafia

o leitor, a quem cabe - por meio do gesto interpretativo da leitura - refazer o elo e retomar a parceria. (Lajolo e Zilberman, 2009: pp 20-21).

\section{Introdução: nosso mote e nossa fonte}

Nesta epígrafe, Lajolo e Zilberman (2009) destacam a relação leitor-texto, imprescindível, para que a escrita (de um livro, de uma reportagem, de um bilhete, etc.; seja no suporte impresso ou digital) possa ser interpretada e se tornar compreensível a quem a lê. Conforme sinalizam, ao leitor cabe "refazer o elo e retomar a parceria [com a escrita]”. Fica visível, nas poucas linhas transcritas das autoras, a importância da proficiência do leitor, pois ele é quem atribui o sentido a partir das informações que o contextualizam. A figura da professora alfabetizadora, embora não mencionada, está implicada na cena descrita. Para que o leitor encontre a chave interpretativa da leitura, atribuindo significados às letras, interpretando os textos, é porque alguém, na sua trajetória alfabetizadora, esteve ao seu lado guiando-o no processo de ler. É na importância do papel da professora - formadora de leitores - que gostaríamos de focar nossa problematização. E na relevância que a formação continuada pode ocupar no processo de alfabetizar letrando, como iremos doravante desenvolver.

Neste artigo, temos como objetivo focalizar alguns dos sentidos conferidos pelas professoras alfabetizadoras sobre a leitura deleite como uma atividade permanente da rotina das práticas pedagógicas desenvolvidas nos encontros de formação continuada de professores. A partir de seus dizeres a respeito de como compreenderam esses momentos desenvolvidos nos encontros de formação, procuramos destacar essa abordagem como uma das formas de se trabalhar a dimensão da leitura (dentro de uma proposta alfabetizadora) em que o sujeito é tomado como alguém que se posiciona frente àquilo que lê e a que vivencia nas práticas formadoras. Leal (2017), em um de seus artigos sobre a alfabetização, sublinha a relevância da inserção dos estudantes em diferentes situações de produção e de compreensão de textos, para que assim se ajude a 
promover a ampliação de saberes, de repertórios culturais e do entendimento sobre os diversos funcionamentos da escrita no cotidiano. Vale ainda ressaltar que essa abordagem - realizar a leitura fruição ${ }^{3}$ nos encontros formativos - tem como um de seus objetivos provocar desdobramentos nas salas de aula dos anos iniciais do Ensino Fundamental. Para tal discussão, tomamos como base de nossas reflexões os resultados do projeto de pesquisa intitulado "Formação, Alfabetização e Letramento: a experiência do Pacto Nacional pela Alfabetização na Idade Certa no contexto do estado de São Paulo"4. Esse projeto teve como escopo analisar a experiência que tivemos frente à coordenação do programa Pacto da Alfabetização na Idade Certa (PNAIC - Portaria 867 de 04/07/2012) desenvolvida na Universidade Estadual de Campinas (UNICAMP) no período de 2013 e 2014. Definimos, portanto, como nossa meta principal acompanhar os efeitos do programa PNAIC através das atividades formativas desenvolvidas com os Orientadores de Estudos $\left(\mathrm{OE}^{5}\right)$ do Estado de São Paulo participantes do Programa pela UNICAMP e o que esta ação formativa possa ter desencadeado como desdobramentos nas práticas alfabetizadoras.

Problematizamos, no referido projeto de pesquisa (GUEDES-PINTO et al, 2013), diversos aspectos constituintes do ensino da língua portuguesa padrão oral e escrita no processo de alfabetização em suas mais variadas dimensões de reflexão. Por conta desse fato, metodologicamente, utilizamos procedimentos variados para alcançar a meta desejada e os objetivos pretendidos.

Tendo em vista a temática trazida pelo PNAIC sobre a alfabetização e pela sua proposta de alfabetizar letrando, isto é, de se ensinar a ler e a escrever tomando-se como referência as práticas sociais de uso da leitura e da escrita, realizamos, como primeiro movimento, uma revisão bibliográfica a respeito dos conceitos de alfabetização e de letramento.

Assumimos a perspectiva qualitativa de pesquisa, procurando assim acompanhar o processo de formação continuada empreendido pela proposta do PNAIC. Por conta de sua característica multiplicadora, tomamos um olhar para o micro, tendo como unidade de análise os encontros de formação desenvolvidos no âmbito da universidade que, pela

\footnotetext{
${ }^{3}$ Leitura fruição, leitura prazer, são tomadas como sinônimos de leitura deleite.

${ }^{4}$ Processo $n^{\circ} 408692 / 2013-8$, vigência 11/2014 a 12/2015. Agradecimento ao CNPq pelo seu financiamento.

${ }^{5} \mathrm{OE}$ se refere aos professores que frequentavam os encontros de formação oferecidos pela Universidade e que posteriormente exerciam o trabalho de formadores de seus colegas Professores Alfabetizadores (PA) de seu próprio município.
} 
forma que se pronunciou dentro do fluxo dessa multiplicação, também esteve imbuída de aspectos macros devido à estrutura e à abrangência da proposta. Entendemos, assim, que por meio da análise do micro estamos também capturando aspectos macro na medida em que na unidade "formação continuada Unicamp" há marcas da proposta de âmbito nacional, assim como o modo de articulação do projeto aos fundamentos gerais do trabalho. Entendemos que a relação micro-macro se realiza na permanente articulação que se constrói no cotidiano das ações formativas desenvolvidas no Programa.

Para o trabalho de campo tomamos como referência as abordagens da pesquisa qualitativa, baseando-nos nos princípios da pesquisa participante (EZPELETA e ROCKWELL, 1989; ESTEBAN 2010), no trabalho com narrativas orais (tendo em conta a perspectiva da História Oral) e escritas (produzidas pelos OE durante os encontros de formação na universidade) e na análise dos demais documentos referentes ao desenvolvimento do programa. Desse modo, a geração de dados da pesquisa abrangeu uma diversidade de fontes - depoimentos orais, produção escrita do gênero relatório, os Cadernos de formação do Programa - que, a partir dos objetivos traçados pelo estudo, foram analisados pela equipe de trabalho ${ }^{6}$.

$\mathrm{O}$ recorte que faremos neste texto se refere à prática de leitura deleite desenvolvida no âmbito da formação e como proposta a ser multiplicada, tendo em vista os relatos sobre as vivências e experiências proporcionadas nos encontros de formação, pelos OE e PA em suas escolas. Para problematizá-la, nos utilizamos, principalmente, de excertos de entrevistas que realizamos durante o trabalho de campo.

\section{A inserção da Unicamp em um programa nacional: histórico, implicações e políticas}

A contemporaneidade da segunda década do século XXI tem se delineado como uma época de transformações rápidas em diversos setores da vida cotidiana, principalmente naqueles que demandam o uso e domínio da língua escrita. O Brasil,

\footnotetext{
${ }^{6}$ Nossa equipe de pesquisa constituiu-se, além de nossa coordenação, dos seguintes membros: Ana Cláudia e Silva Fidelis, Daniela Gaspar Pedrazzoli Bagnasco, Danieli Sebastiana Oliveira Tasca, Fabiana BigatonTonin, GioavanaAzzi de Camargo, Heloísa Helena Dias Martins Proença e Lígia Formico Paoletti.
} 
embora seja reconhecido como um país que acompanha e participa do avanço das tecnologias da informação, não apresenta uma correspondência desse avanço na área educacional, inclusive em relação ao domínio da leitura e da escrita, desde as situações mais corriqueiras de seus usos sociais, às necessidades que demandam maior conhecimento linguístico na comunicação.

Considerando os dados do Censo 2010,

[...] 13,9 milhões de jovens, adultos e idosos não sabem nem ler nem escrever: 9,6 por cento da população de 15 anos ou mais; 671 mil crianças de 10 a 14 anos não sabem nem ler nem escrever: 3,9 por cento da população nessa faixa etária. Apesar de a taxa do segundo grupo ter caído de 7,3 por cento em 2000 para 3,9 \% em 2010, não há muito a comemorar, já que o desejável seria que as crianças estivessem alfabetizadas até os 8 anos de idade". (PRADO; NÓBREGA, 2012)

Temos assim um panorama desafiante em termos de alcance da alfabetização das crianças brasileiras. O PNAIC tinha, como uma de suas metas, melhorar tais indicadores. Ao mesmo tempo, pode-se sinalizar um avanço no que diz respeito à universalização de acesso ao ensino fundamental bem como à permanência desses alunos nas escolas públicas brasileiras. Tal avanço com relação ao alcance cada vez maior de brasileiros com maior tempo de escolarização também é reconhecido quando se observam os resultados do INAF (Indicador de Alfabetismo Funcional) 2011. Nele ainda se identifica que os escores de alfabetismo básico dos brasileiros foi ampliado, ao mesmo tempo que o seu nível pleno não obteve muitos progressos (LIMA et al, 2015). Embora apresente elementos que mostrem algumas etapas relativamente vencidas (como a queda vertiginosa no escore de analfabetismo absoluto e o aumento do alfabetismo básico), também indica que muitos desafios para o sistema escolar permanecem para todos os envolvidos, como é o caso da prática de leitura.

Observamos ainda que avançamos no sentido de assumirmos um compromisso com a educação de crianças e jovens dos 04 aos 17 anos de idade ${ }^{7}$, o que implica um salto em relação à assunção do Estado do compromisso com a educação básica (fundamental e Médio). Dentre os vários aspectos que podem ser problematizados, destacamos, neste texto, o desafio de as escolas públicas garantirem às crianças e aos jovens o direito de aprenderem e se desenvolverem plenamente, o que inclui o direito de

\footnotetext{
${ }^{7}$ Lei 12.796 - abril de 2013.
} 
serem alfabetizados. Como sinaliza Freitas (2003, p. 151), o grande desafio nesse processo de ampliação e de qualificação do aprendizado em nosso país se volta a reverter o quadro em que a exclusão é internalizada, ou seja, quando o aluno permanece na instituição escolar mesmo sem aprender.

Com a ampliação do Ensino Fundamental $^{8}$ de oito para nove anos de escolaridade, as publicações do Ministério da Educação (MEC) ${ }^{9}$ em 2007 já apontavam para que a mudança no sistema de organização do ensino se refletisse na qualificação da aprendizagem, da alfabetização e do letramento das crianças (BRASIL, 2007a, p. 8). Segundo o MEC, entre os objetivos da ampliação dos anos escolares obrigatórios está o de assegurar às crianças (todas) mais tempo de convívio escolar, garantindo maiores oportunidades de aprendizagem.

No contexto atual, com a obrigatoriedade da escolarização dos 04 aos 17 anos, como já mencionado, a intenção é que haja oportunidade de as crianças terem seus direitos à infância com dignidade. Isso implica que

A proposta pedagógica das instituições de Educação Infantil deve ter como objetivo garantir à criança acesso a processos de apropriação, renovação e articulação de conhecimentos e aprendizagens de diferentes linguagens, assim como o direito à proteção, à saúde, à liberdade, à confiança, ao respeito, à dignidade, à brincadeira, à convivência e à interação com outras crianças" (BRASIL, DCN, 1999).

Diante desses objetivos, consideramos que o PNAIC vem ao encontro desses princípios. Não se constitui, portanto, como um Programa que se limita à alfabetização na "idade certa", ou somente estimule a antecipação escolar das crianças da creche e pré-escolas.

A incorporação das crianças de seis anos ao Ensino Fundamental e a obrigatoriedade da educação escolar a partir dos quatro anos demanda, por parte dos dirigentes que integram os governos e, principalmente, dentre os movimentos sociais,

\footnotetext{
${ }^{8}$ Para esta ampliação a Lei 11.274/2006 alterou o art. 32 da Lei de Diretrizes e Bases da Educação - LDB (Lei 9.394/1996), implantando a matrícula obrigatória de crianças de seis anos nas escolas de ensino fundamental, tanto nas escolas públicas como nas escolas privadas do país. O prazo para os municípios, os estados e o Distrito Federal se adequarem à nova legislação foi o ano de 2010.

${ }^{9}$ Entre diversas publicações podemos enumerar algumas como: Ensino fundamental de nove anos: orientações para a inclusão da criança de seis anos de idade. Brasília: MEC (Secretaria de Educação Básica). Material do Pró-letramento: Programa de formação continuada de professores dos anos/séries iniciais do ensino fundamental - Alfabetização e linguagem. Brasília: MEC (Secretaria de Educação Básica).
} 
profissionais da educação e familiares, um amplo debate sobre a concepção de sociedade-educação que vem sendo vivenciada e "defendida" nas instituições escolares. Há que se superar a crítica pela crítica e a sua defesa "cega". O papel da universidade, dentre outros atores sociais, nesse contexto, faz-se imprescindível e necessário.

A inclusão das crianças aos seis anos no Ensino Fundamental desafiou os educadores a definir com maior clareza o que se espera da escola nos anos iniciais de escolarização, dessa forma, estamos passando por uma reorganização do trabalho pedagógico nesse segmento do ensino. Segundo os documentos do MEC, delineia-se uma grande questão quanto à delimitação de conhecimentos, habilidades e capacidades a serem contempladas nas propostas curriculares. Em materiais dos programas de formação continuada de professores como o Pró-Letramento, no Guia do Programa Nacional do Livro Didático (PNLD), do ponto de vista do MEC, os cinco primeiros anos do Ensino Fundamental têm como tarefa básica ampliar o universo de referências culturais das crianças, bem como contribuir para ampliar e aprofundar suas práticas de letramento.

Os professores dos anos iniciais constituem-se como mediadores do processo de apropriação da linguagem, assim como são responsáveis por valorizar, reconhecer e trabalhar com os saberes das crianças que ingressam no Ensino Fundamental. Diante disso, o grande desafio concentra-se no trabalho de organizar o trabalho pedagógico de modo que as crianças tenham acesso à diversidade de gêneros que circulam em diferentes esferas sociais, favorecendo seu ingresso ao mundo da escrita e sua participação em situações de uso efetivo da linguagem.

Outro ponto basilar do PNAIC que se destaca em sua proposta é o fato de apoiar-se na formação continuada. O Programa toma como premissa fundamental contribuir para o aperfeiçoamento da formação dos professores alfabetizadores. Nesse contexto de formação, os docentes são compreendidos como sujeitos participantes e interlocutores no processo de construção tanto de seus saberes profissionais e teóricos quanto nos encaminhamentos propostos no ambiente escolar. Complementando ainda, os professores, nessa perspectiva, são entendidos como sujeitos autores de seus trabalhos. Para que esse viés pudesse ser incorporado no trabalho formativo junto a eles, os materiais produzidos, qual seja, os Cadernos, procuraram elaborar uma proposta que dialogasse com a produção acadêmica que embasasse essa forma de conceber a formação de professores. Segundo sublinhado por Evangelista, Bagnasco e Tasca 
(2016: p. 197), “o PNAIC contempla alguns princípios na/para formação de professores, tais como: prática da reflexividade, mobilização dos saberes docentes, constituição da identidade profissional, socialização, engajamento e colaboração". As autoras argumentam que tais princípios estimulam e favorecem o trabalho sistemático de análise, por parte do professor, de seu próprio trabalho junto às crianças. Além de também de incentivarem um olhar para si próprio como profissional, para sua relação com a comunidade da escola, para sua relação com seus pares, com sua categoria profissional.

Diante, portanto, das premissas apresentadas pelo Programa, a UNICAMP avaliou a importância de assumir, juntamente com a Universidade Estadual Paulista (UNESP) () e a Universidade Federal de São Carlos (UFSCAR), a parceria com o governo federal no sentido de contribuir para a implementação do PNAIC. Como instituição social de ensino, pesquisa e extensão que busca congregar e consolidar suas "vocações políticas e acadêmicas" (CHAUI, 2001), consideramos que a UNICAMP poderia fortalecer essa parceria com o governo federal, estados, municípios e demais entidades comprometidas com a finalidade de oportunizar e garantir o direito à alfabetização de crianças, nos anos inicias do ensino fundamental.

Por se tratar de um Programa de amplitude e envergadura nacional, envolvendo os 26 estados e o distrito federal, 5.565 municípios de todo o país; sendo 645 municípios do estado de São Paulo; a Unicamp ponderou que sua participação priorizaria a viabilidade da parceria com ênfase na manutenção e garantia da qualidade dos trabalhos desenvolvidos ao longo do processo de implantação e implementação no/do Programa. Nesse contexto, nos responsabilizamos, em 2013, pela formação de 86 municípios, com $361 \mathrm{OE}$ que se responsabilizariam pela formação junto aos professores alfabetizadores (PA) em seus respectivos municípios. No total organizamos 13 turmas, que foram acompanhadas sistemática e periodicamente pela equipe de coordenação (pedagógica, "administrativa” e de "supervisão" pedagógica e formativa).

O início do PNAIC, no contexto da UNICAMP, como responsável pela Formação das OE, se deu via Reitoria da Universidade - Pró-Reitoria de Graduação. Embora tenha ocorrido transição dos dirigentes da UNICAMP nesse período, o Programa transcorreu contando com o apoio institucional, político e econômico da UNICAMP. Para exemplificarmos esta afirmativa, faz-se importante mencionar que os recursos para a realização do PACTO/UNICAMP foram enviados à Universidade 
somente após junho de 2013. No entanto, com o intuito de cumprir o cronograma de trabalho previsto, a instituição assumiu todos os encargos das formações que foram realizadas no período de fevereiro, maio e junho do referido ano, inclusive os custos de locomoção, alojamento das formadoras, durante as formações e em outras datas previstas para o planejamento das formações. Acrescido a este fator, foi imprescindível para o seu desenvolvimento, o apoio efetivado pela equipe da Comissão Central de Graduação (CCG/ Comissão Permanente de Formação de Professores/Pró-Reitoria de Graduação).

Em dezembro de 2013 foi acordado que a formação no PNAIC 2014 aconteceria na perspectiva da integração entre as áreas de Língua Portuguesa e Matemática. A UNICAMP, a pedido do MEC, ampliou o número de turmas: de 13 para 24, chegando a 148 municípios e mais de 600 orientadores de estudo, de 13 formadores para 48, de 3 supervisoras para 9, de uma coordenação adjunta para duas. Ou seja, todos esses números indicam um crescimento significativo de toda a equipe.

O Programa, em 2014, foi viabilizado com verba orçamentária residual de 2013, em virtude de o empenho 2014 não ter sido formalizado e o recurso não ter sido transferido no prazo estipulado. Em meados de junho de 2014, tivemos outra mudança administrativa: o PNAIC passou a ser executado institucionalmente pela Faculdade de Educação.

Consideramos oportuno mencionar que a participação da UNICAMP no contexto do PNAIC não se constitui como ação isolada. Entendemos que o Programa não se apresenta como algo "novo" 10 , mas tem como um de seus atributos a centralidade na formação de professores como seu eixo central, o que o torna relevante em nossa ação institucional.

A proposta formativa do PNAIC apresentou um conjunto de possibilidades pedagógicas que provocam e convidam o professor a vivenciar diferentes estratégias de aprendizagem que visam à alfabetização das crianças nos anos iniciais do ensino

\footnotetext{
${ }^{10}$ Exemplos de outros programas de Governo voltados à alfabetização no Brasil: 1999: PCN em Ação Alfabetização Governo Federal, 2000: GESTAR - Programa Gestão da Aprendizagem Escolar Governo Federal, 2001: PROFA - Programa de Formação de Professores Alfabetizadores Governo Federal, 2003: PRALER - Programa de Apoio a Leitura e a escrita Governo Federal, 2005: PRÓ-LETRAMENTO Programa de Formação Continuada de Professores dos Anos/Séries Iniciais do Ensino Fundamental Alfabetização e Linguagem, 2007: PAIC - Programa pela Alfabetização na Idade Certa / Governo do Estado do Ceará, 2008: Programa Além das Palavras / Governo do Estado de Mato Grosso do Sul, 2012: PNAIC - Pacto Nacional pela Alfabetização na Idade Certa Governo Federal
} 
fundamental, de forma plena, ou seja, considerando desde as especificidades do Sistema de Escrita Alfabética (SEA), tendo por base as questões do seu sistema linguístico, até as práticas de uso da linguagem em suas diversas situações e manifestações socioculturais.

Tomando a questão da problematização do emprego da língua, tendo em vista as propostas de trabalho pedagógico dentro do Programa, como um de seus de objetivos a serem alcançados, nos deparamos com desafios: garantir acesso aos diferentes gêneros discursivos que circulam socialmente desde o início da escolarização das crianças, contribuindo para o desenvolvimento das capacidades de leitura e de produção de textos, considerando-as como protagonistas de suas próprias histórias; e, também, garantir a ampliação de seu universo cultural, de forma que possam ouvir, falar, ler, escrever sobre os mais variados temas.

Para enfrentar esses desafios, nos materiais produzidos pelo Programa, como os Cadernos do PNAIC, a prática de leitura deleite pareceu-nos representar um potencial a ser utilizado como recurso pedagógico frente a eles. Ela está descrita como uma atividade didática permanente da ação dos professores em sala de aula. É sobre ela que iremos nos deter.

\section{A leitura deleite como proposta de atividade permanente na sala de aula}

No Caderno Ano 01 Unidade 02 do PNAIC, a leitura na escola é referida como uma prática essencial do cotidiano da sala de aula, segundo consta no texto apresentado no material, "ler para nossos alunos é prática fundamental para despertar o gosto e o desejo pela leitura" (MAGALHÃES ET AL, 2012: p. 08). Nesse Caderno, as autoras destacam a importância da organização de uma rotina de trabalho junto às crianças de forma que seja garantida a elas diariamente a experiência de ouvir uma história lida pelo seu professor. Ressaltam o papel de práticas de trabalho em sala que, juntas, favorecem o processo de alfabetização, tais como a leitura oral cotidiana de textos de diversos gêneros, a produção de textos, trabalhos com a oralidade, a análise linguística com vistas à apropriação do sistema de escrita alfabética. Importante salientar que tais recomendações vão ao encontro de orientações de Programas de formação anteriores, 
como o PROFA e o Pró-Letramento, assim como reforçam propostas antigas de trabalho com o ensino da língua portuguesa no sentido de buscar dialogar com as várias práticas sociais de uso da língua escrita.

Tomando a prática de leitura como um eixo constitutivo do currículo dos anos iniciais do Ensino Fundamental I, Magalhães et al (2012) apresentam depoimentos de professoras alfabetizadoras a respeito de como organizam suas aulas e de como conferem significado a essa prática. Ferreira e Albuquerque (2012), no mesmo Caderno, também apresentam depoimentos para exemplificar diversas propostas de possibilidades de construção de uma rotina para o trabalho pedagógico, enfatizando o papel do planejamento didático no contexto da docência para os pequenos. Ao analisarem, por exemplo, um quadro síntese sobre a rotina de atividades desenvolvida por uma das professoras que forneceu seu depoimento, as autoras sinalizam alguns aspectos:

\begin{abstract}
Queremos ressaltar que a organização de uma rotina que privilegia a sistematização do trabalho de alfabetização de modo a contemplar os diferentes eixos de ensino da língua, por meio de um planejamento construído com base na realidade de cada aluno e escola, pode favorecer a construção e a realização de atividades que ajudam a promover a autonomia e a criatividade dos alunos no mundo da leitura e escrita (FERREIRA e ALBUQUERQUE, 2012, p. 27).
\end{abstract}

A sistematização do ensino é tomada como um fundamento da ação didática nos anos iniciais. Sistematizar o trabalho pedagógico, dentro da proposta do PNAIC, significa assumir a função do planejamento como um recurso basilar do professor. Ao planejarmos o que fazer junto às crianças no cotidiano escolar estamos ao mesmo tempo realizando escolhas e priorizando momentos em sala de aula para desenvolvermos certas atividades, e não outras. Ou seja, ao planejar nossas ações didáticas tornamos visível nossos critérios para a organização do período escolar e, assim, expressamos, na rotina finalizada ao fim do dia, como foi usado o tempo em sala de aula, quais foram nossas opções (GUEDES-PINTO ET AL, 2007).

Retomando ainda a fala da professora entrevistada, presente no texto de Ferreira e Albuquerque (2012) no Caderno já citado do PNAIC, ela descreve algumas atividades permanentes que fazem parte do seu planejamento e que ela desenvolve com sua turma. A professora explica que se trata de atividades feitas pelo grupo com regularidade como, por exemplo, a leitura de um livro. Ferreira e Albuquerque (2012) sinalizam que a organização do trabalho pedagógico envolve procedimentos que são intencionais, ou 
seja, que o professor selecionou para desenvolver determinada atividade para atingir determinado objetivo com seus alunos. Acrescendo-se a isso, é importante lembrar que tais procedimentos são escolhidos para que sejam possíveis as articulações com as práticas socioculturais da turma, isto é, para que as atividades em sala de aula ou fora dela propiciem a construção de relações com os conhecimentos prévios de cada criança. A intencionalidade pedagógica, nessa perspectiva, ganha ainda mais relevância, pelo fato de ela estar focada em estabelecer condições favoráveis ao encaminhamento do trabalho pedagógico junto aos alunos.

Os Cadernos do PNAIC, conforme enfatizado, assumem como um de seus eixos o trabalho com a leitura no processo de alfabetização, tendo em vista a prática social. Cabe, então, à escola e aos professores, garantir a realização dessa prática. "O professor que lê para seus alunos eleva as chances de este ter experiências leitoras únicas e significativas, deixando marcas que facilitarão a compreensão da leitura”, reafirmam Evangelista, Bagnasco e Tasca (2016: p. 201) sobre o nosso papel na mediação pedagógica, particularmente no que concerne ao ler. A leitura deleite, apresentada nos materiais do PNAIC como uma atividade permanente a ser incorporada nas práticas alfabetizadoras da escola brasileira, tornou-se para nós, equipe formadora da UNICAMP/PNAIC, uma estratégia formativa central em nossos encontros com os OE.Tal estratégia se pautou, em um dos seus pilares, na característica de a formação continuada proposta pelo Programa ter um caráter multiplicador. Dito de outra forma, apostamos no princípio de desenvolver práticas de trabalho com os OE que poderiam ser reconstruídas por eles ao ocuparem o lugar de formadores de seus pares quando fossem conduzir os encontros em seus respectivos municípios. Fidelis e Tonin (2016: p. 227) enumeram aspectos relativos ao processo formativo vivenciado no período de 2013 e 2014 com os OE e pontuam:

Nesse sentido, nas formações do PNAIC, foi fundamental o papel desempenhado pelos formadores: as escolhas das obras que integraram a concretização da estratégia formativa da leitura deleite contou sempre com escolhas pessoais, mas também com o olhar cuidadoso do especialista que pensava tanto nos alunos (público principal do programa), como nos OEs e nos professores, considerando-se permanentemente a ideia fundadora do professor como modelo de leitor.

As autoras focalizam o trabalho de escolha sobre o que ler para os professores em formação e destacam a importância em torno do processo de seleção das leituras a 
serem desenvolvidas junto a cada grupo, como estratégia formativa. Também destacam o momento vivido dessa leitura deleite a ser compartilhada. Referindo-se à concepção formativa que subsidiava a perspectiva do PNAIC/-UNICAMP, complementam (FIDELIS e TONIN, 2016: p. 226):

[a concepção formativa do PNAIC] considera também a relevância da ampliação do repertório de leitura de orientadores de estudos e professores alfabetizadores, bem como da postura de assumir-se como modelo de leitor, ocupando o lugar de porta-voz do texto, responsabilizando-se por sua transmissão aos seus ouvintes.

A orientação que seguimos para desenvolver nossa ação procurou sensibilizar os OE tanto para os aspectos da fruição e possibilidade de apreciação estética dos textos lidos quanto para a importância do trabalho de escolha, que envolve critérios (de ordem pessoal e também sobre a qualidade do texto) de avaliação, da leitura deleite realizada. Buscamos assim problematizar a relação entre planejamento e leitura para o prazer e ressaltar o quanto esses dois pontos - o planejar e o fruir - da leitura podem estar interligados, favorecendo a possibilidade de multiplicação dessa prática.

\section{Sentidos atribuídos pelas professoras alfabetizadoras à prática de leitura deleite}

Conforme dito no início deste artigo, problematizaremos alguns dos resultados da pesquisa citada sobre o trabalho formativo desenvolvido pelo PNAIC/UNICAMP em 2013 e 2014 e seus efeitos, em especial, sobre os Professores Alfabetizados (PA) que participaram do Programa em seus respectivos municípios.

Como informado antes, em relação à abordagem metodológica do projeto, o desenvolvimento do trabalho de campo tomou como referência a pesquisa participante, baseando-se na pesquisa-ação, tendo em conta a investigação do próprio trabalho de formação protagonizado pelos professores-formadores da universidade; com narrativas orais e escritas, desenvolvido pelos professores Orientadores de Estudos (OE) e produzido durante os encontros de formação na universidade, pelos PA em seus municípios e na análise dos demais documentos referentes ao desenvolvimento do programa. 
Aqui nos deteremos apenas nos depoimentos orais produzidos no contexto de entrevistas realizadas no ano de 2014 com PA de diferentes municípios do estado de São Paulo e que participaram do Programa sob nossa responsabilidade.

Conforme já mencionado, a perspectiva da História Oral (HO) nos forneceu subsídios para a condução das entrevistas. Tomamos como procedimento padrão construirmos um roteiro básico de entrevista com os PA para todas as pesquisadoras que foram a campo. Tal roteiro incluía o modo de iniciar a conversa - sempre apresentando as características do projeto, seus objetivos, para que a PA entrevistada ${ }^{11}$ tivesse condições de se situar a respeito de nossa procura para ouvirmos seu depoimento. Portelli (2001), pesquisador italiano, com muitos trabalhos de rememoração sobre a Segunda Guerra, com base na $\mathrm{HO}$, discute em minúcias a relação pesquisadorpesquisado e aborda a questão do equívoco criado a partir do mito da não-interferência, quando se acreditava que quanto menos o entrevistador interferisse e se expusesse durante a entrevista, mais objetividade e dados confiáveis seriam obtidos. $\mathrm{O}$ autor afirma que a confiança e a cumplicidade, tão importantes na relação de entrevista na perspectiva da $\mathrm{HO}$, se constroem justamente por conta de o entrevistador apresentar ao sujeito entrevistado quem ele é, de que lugar social fala, quais seus interesses dentro da pesquisa e por que o chegou até ali. Sobre isso, Portelli conclui, assinalando para o caráter ético que envolve o trabalho da pesquisa com HO: "Uma troca pessoal torna-se uma declaração pública que pode ser um processo perfeitamente legítimo, quando isto é o que buscam ambos os lados" ((2001: p. 23; grifos do autor).

Em nossas entrevistas, dentro do roteiro que nos ajudava a guiar nossas indagações com nossos objetivos, contemplávamos a abordagem aos eixos de trabalho privilegiados pelo Programa. Procuramos, então, perguntar sobre as práticas de leitura deleite, sobre o trabalho com os gêneros textuais, sobre a produção de textos e, ainda, sobre a apropriação das crianças do sistema de escrita alfabética. Esses pontos a serem tocados nas conversas com as PA poderiam, acreditávamos, nos trazer elementos a respeito de desdobramentos do Programa. Assim, buscamos nos aproximar de suas compreensões a respeito das estratégias da formação, compartilhando, nesse sentido, do posicionamento de Andrade (2017) ao desenvolver sua pesquisa-formação, tal como a autora a define junto às professoras da escola básica, quando imersas em cursos de

\footnotetext{
${ }^{11}$ Todas os sujeitos das entrevistas são constituídos por mulheres.
} 
formação continuada. Ela defende uma abordagem dialógica nas formas de proceder na pesquisa, destacando sua preocupação no olhar para como as professoras recontextualizam seus aprendizados. Assumindo a perspectiva bakhtiniana, Andrade (2017) busca as contrapalavras ${ }^{12}$ produzidas pelas professoras às propostas de trabalho vindas da universidade. Acreditamos, tal como conceitua Andrade (2017), que as professoras também produzem seu processo autoral de formação. Passamos, então, a seguir, para a problematização de suas narrativas.

Nos fragmentos que selecionamos, as PA se referem especificamente à leitura deleite. Os dois trechos seguintes apresentam as falas de duas PA, ambas do mesmo município - Bragança Paulista - revelando um parecer bastante distinto entre elas em relação à proposta da vivência da leitura deleite no âmbito das formações. Enquanto a primeira atribui um valor positivo à dinâmica, a segunda não reconhece sua importância:

$\mathbf{E}^{\mathbf{1 3}}$ : E a dinâmica dos encontros, como que era?

PA: Ah, era gostoso até. Porque a gente começava com a leitura, né, que ela [a formadora $\mathrm{OE}$ ] sempre trazia. A minha formadora foi a ....... Ela trazia uma história, lia pra gente, passando slide, assim .... Era uma nova forma, talvez, de apresentar o livro para as crianças. (Entrevista com PA de Bragança Paulista, 2014)

[...]. E é uma coisa que, no meu grupo, eu sentia que não despertava tanto a atenção [a leitura deleite]. Porque grande parte das histórias, pra quem já é professor há muito tempo, é conhecida. Pra quem tem acesso. Eu sempre tive muito acesso a livros, então, assim, não é cansativo, mas poderia já ser usado, como o tempo é curto, um outro tipo de atividade. (Entrevista com PA de Bragança Paulista, 2014)

Portelli (2001) ressalta a característica de a HO procurar trabalhar com várias vozes, no mínimo duas (a do historiador oral e a do entrevistado), ou com muitas. Alberti (2004: p. 46), pesquisadora brasileira com trabalhos diversos sobre a HO (desde questões de ordem metodológica a questões de rememorações), faz uma ponderação importante a esse respeito da preservação de vozes:

\footnotetext{
12 Explicando de forma simples, podemos dizer que o termo bakthiniano "contrapalavras" designa as palavras de cada sujeito produzidas na relação discursiva dialógica com outro sujeito (que pode também ser uma instituição), ou seja, as contrapalavras se referem às réplicas que cada um de nós elabora na relação com os outros.

${ }^{13}$ A letra E se refere ao turno de fala da entrevistadora.
} 
Não há dúvida de que a história oral permite o registro de uma quantidade diversificada de narrativas de experiência de vida, viabilizando o acesso a visões de mundo e a histórias de vida provenientes de diferentes grupos sociais. Na medida em que se entende esse pluralismo como democracia, pode-se seguramente afirmar que a instituição do campo da história oral foi um passo importante no sentido da democratização do registro e do acesso a narrativas de experiência pessoal.

Embora a autora focalize suas afirmativas tendo em vista o trabalho com histórias de vida ${ }^{14}$, ela destaca a contribuição da HO no sentido de trazer para a história oficial a narrativa de pessoas comuns e de apresentar diferentes pontos de vista para um mesmo tema, para um mesmo problema. No nosso caso, como demarcado anteriormente, o tema focado se volta à prática de leitura deleite proposta pelo PNAIC e assumida pela equipe formadora da UNICAMP como uma estratégia formativa dos encontros. Nossos sujeitos são as PA que, na configuração multiplicadora do Programa, representam o último elo da cadeia da proposta formadora, antes de chegar aos alunos. Cada uma delas apresenta uma forma particular de entender o papel da prática de leitura deleite nos encontros de formação.

O primeiro excerto traz a fala da PA qualificando o momento da leitura deleite nas formações com a OE como algo prazeroso (era gostoso até, ela diz). Junto disso, além de mencionar que se tratava de uma atividade regular, a professora ainda comenta que, para ela, foi uma novidade o livro ser lido por meio de um outro suporte, o projetor (Ela trazia uma história, lia pra gente, passando slide). Na continuidade dessa mesma entrevista a PA pontua que já tinha incorporado a prática de leitura em sua sala com os alunos, mas reconhece que a dinâmica da leitura deleite contribuiu para que ampliasse o repertório de histórias para ler para eles, assim como para aprender formas diversas de trabalhar com a leitura, como o uso de fantoches ou do projetor para mostrar as páginas dos livros.

Já no segundo fragmento, o dizer da PA indica um tom apreciativo negativo à leitura deleite que acontecia no seu grupo de formação com a OE: não é cansativo, mas poderia já ser usado, como o tempo é curto, para um outro tipo de atividade. Na sequência da entrevista realizada, a professora reforça esse seu posicionamento e complementa: E, pra quem costuma ler bastante, né, então, não prende muito aquilo

\footnotetext{
${ }^{14}$ Dentro do campo da HO há uma série de definições para cada tipo de abordagem: história de vida, história temática, tradição oral, etc. Entre os próprios pesquisadores não há consenso entre essas definições. Portanto, está fora do escopo deste artigo nos determos nessas diferenciações.
} 
dali. Poderia, esse momento, ser citado o livro, né. Não haveria a necessidade de o orientador [OE] fazer a leitura, porque é uma leitura voltada para a criança.

Assim, nestes excertos, identificamos que, apesar de as duas PA participarem da mesma rede de ensino, seus modos de se referir à estratégia de formação experienciada por elas divergem, dando corpo ao que Portelli (2001) e Alberti (2004) assinalam a respeito de como as narrativas podem fornecer pistas para entendermos que uma mesma vivência pode receber olhares diferentes, construídos, portanto, pelas subjetividades instanciadas em cada sujeito.

Retomando ainda esses dois trechos, a partir da perspectiva discursiva defendida por Andrade (2017: p. 300), podemos reconhecer nessas diferenças de sentidos atribuídos pelas professoras a esse momento da leitura deleite, seus modos particulares de construírem sua autoria. Ela pondera a respeito:

O dialogismo entre formadores e formandos (ou constantemente formados?), a partir de um discurso de formação que se tece entre interações de conhecimentos sobre a língua e saberes da escola, faz emergir o que consideramos como a vida da formação, que move os discursos intervenientes na rede que tensiona o campo social ou a esfera discursiva.

No terceiro fragmento selecionado das narrativas a ser problematizado, a PA de Jundiaí responde à pesquisadora, sobre o que consideraria como algo novo, a prática de leitura:

E: E tem algum tema, algum conceito trabalhado, alguma atividade que te chamou mais a atenção, que você teve um novo olhar a respeito daquilo, ou que foi novidade?

C: É, acho que, novidade, assim, não teve nenhuma, mas de novo olhar foi a de leitura mesmo. Eu te falei, porque a gente tem muita atividade escrita. né? $\mathrm{E}$ esquece um pouquinho desse lado da leitura.[...]. Agora eu tenho procurado oferecer aos alunos. Mais atividades de leitura mesmo. (Entrevista com PA, Jundiaí, 2014)

Os dizeres da professora indicam que o Programa, no seu ponto de vista, não apresentou propostas novas. Entretanto, reconhece que em relação à leitura, houve um "novo olhar". Sua fala torna também visível o impacto da formação do PNAIC no sentido de ter provocado um aumento nas atividades de leitura no cotidiano da 
professora (Agora eu tenho procurado oferecer aos alunos. Mais atividades de leitura mesmo).

No quarto, e último, fragmento a ser analisado, a PA de outro município, Louveira, conta que também ampliou seu repertório de textos, reforçando os dizeres das professoras de Bragança Paulista e de Jundiaí:

E: E em relação à leitura à deleite, daquilo que era pensado, ou daquilo que foi partilhado na formação, você conseguia levar para a sua sala de aula a questão da leitura à deleite?

R: Sim. Tiveram até vários livros que eu acabei adquirindo, comprando, que eu achei muito interessante. Achei que seria muito bom para as crianças. Eu uso até hoje. Que, assim, livros que eu não conhecia, vim a conhecer lá, através das colegas e que, assim, deu um grande resultado.

(Entrevista com PA, Louveira, 2014)

Sua fala apresenta uma reflexão sobre o uso da estratégia da leitura deleite nos encontros de formação ao reconhecer que permitiu um contato com um maior número de títulos e que tal estratégia, utilizada no grupo de PA, ao ser coletiva, propiciou esse compartilhar de conhecimentos sobre os livros (livros que eu não conhecia, vim a conhecer lá, através das colegas e que, assim, deu um grande resultado). Seu relato, portanto, corrobora a ideia de que viver a prática do princípio estipulado - leitura deleite como prática de ensino permanente - pode ser um modo de os professores se sensibilizarem para a importância de tal princípio para guiar o cotidiano pedagógico junto aos alunos. Sua fala ainda traz a informação de que ela adquiriu livros para si, comprando-os a partir do que conheceu nos encontros. Esse aspecto pode ser avaliado como um resultado de intervenção muito valioso, uma vez que os indicadores do INAF 2011 apresentam um quadro preocupante quanto à aquisição e à leitura de livros pelos brasileiros (BATISTA, VÓVIO e KASMIRSKI, 2015). Nesse sentido, tal relato oferece a percepção de um pequeno efeito que uma experiência formadora pode produzir. Tendo em vista que esse Programa atingiu um espectro bastante numeroso de sujeitos, como descrito nas primeiras seções deste artigo, somada ainda à questão multiplicadora de seus desdobramentos, essa informação pode ser tomada como uma rica contribuição na direção de intervenções mais potentes para o desenvolvimento de futuros programas de formação. 


\section{Leitura deleite como prática formadora. Contribuições possíveis do PNAIC/UNICAMP}

Retomando os fragmentos aqui analisados, vemos que os dois primeiros apresentam olhares diferentes para a prática de leitura deleite vivida na formação do PNAIC, visibilizando as questões singulares que compõem cada dizer. As duas professoras mencionaram já ter conhecimento dessa estratégia didática como proposta de ensino. No entanto, uma delas significou essa maneira de proceder da OE - ler um livro antes de começar o encontro - nas formações de seu município, enxergando nesse gesto as novidades em algo que já lhe era familiar. A outra professora, talvez por considerar-se um sujeito leitor proficiente, com sua formação concluída, e citar que seu grupo se constituía de leitores formados, não atribui valor a essa estratégia formativa usada pela OE. Ambas as professoras, tendo por base o viés explicativo defendido por Andrade (2017), recontextualizam a experiência vivida dialogando com suas próprias referências - enunciando-se, portanto, responsivamente, elaborando de forma autoral, com suas contrapalavras, seus entendimentos do papel da leitura deleite.

Os fragmentos de narrativa das professoras de Jundiaí e de Louveira, por sua vez, dão visibilidade ao reconhecimento de que o uso de uma prática já conhecida pode proporcionar descobertas e possibilidades de ganho profissional para os professores. Fidelis e Tonin (2016: p. 229), tecem as seguintes considerações:

Considerando os recentes estudos sobre letramento literário, a prática da leitura deleite, não apenas nos espaços formativos, mas como prática a ser adotada pelos professores alfabetizadores em sua realidade docente, corrobora a construção de uma comunidade de leitores, elemento essencial para as práticas de letramento e da leitura literária, que compartilha textos, autores, convenções do universo literário bem como seus protocolos de leitura.

Acreditamos que esse recorte dos resultados alcançados pela pesquisa fornece indicadores que nos mantêm determinadas a continuar nos orientando por princípios de ação didática já compartilhados e familiarizados pelos professores. Os relatos das professoras alfabetizadoras contêm pistas que reforçam nossa aposta na insistência de princípios de trabalho, mesmo sendo considerados relativamente "antigos", tal como o da leitura deleite como uma dimensão potencializadora da prática formadora docente. 
Voltando à epígrafe deste artigo, esperamos, apoiadas em Lajolo e Zilberman (2009), que o gesto interpretativo dos leitores frente aos desafios apresentados pela escrita possa sempre ser refeito e reelaborado por um número cada vez maior de sujeitos leitores. Esperamos ainda que, a parceria entre os leitores e seus textos (sejam eles quais forem, nas suas mais diferentes materialidades escritas) tenha nas professoras alfabetizadoras mediações possíveis para que tais gestos interpretativos se multipliquem.

\section{Referências bibliográficas}

ALBERTI, Verena. Ouvir contar: textos em história oral. Rio de Janeiro: Editora FGV, 2004.

ANDRADE, Ludmila Thomé de. Por uma formação de professores em moldes discursivos. In MACEDO, Maria do Socorro Alencar Nunes e GONTIJO, Cláudia Maria Mendes. (orgs.) Políticas e práticas de alfabetização. Recife: Ed. UFPE, 2017.

BATISTA, Antonio Augusto Gomes, VÓVIO, Cláudia e KASMIRSKI, Paula Reis. Práticas de leitura no Brasil, 2001-2011: um período de transformações. In RIBEIRO, Vera Masagão; LIMA, Ana Lúcia D'Império e BATISTA, Antônio Augusto Gomes (orgs) Alfabetismo e Letramento no Brasil: 10 anos do INAF. Belo Horizonte: Autêntica Editora, 2015.

BRASIL. Ensino fundamental de nove anos: orientações para a inclusão da criança de seis anos de idade. Brasília: MEC (Secretaria de Educação Básica), 2007.

BRASIL. Diretrizes Curriculares Nacionais, Ministério da Educação, 1999.

CHAUÍ, Marilena. Escritos sobre a Universidade. São Paulo: Editora Unesp, 2001.

ESTEBAN, Maria Paz Sandín. Bases conceituais da pesquisa qualitativa. In: ESTEBAN, Maria Paz Sandín. Pesquisa Qualitativa em Educação: Fundamentos e Tradições. Porto Alegre: AMGH, 2010, cap. 6, p. 122-191.

EVANGELISTA, Cristiane B.; BAGNASCO, Daniela G. Pedrazzoli e TASCA, Danieli S. Oliveira. O ensino sistemático de leitura nos anos iniciais do ensino fundamental e a formação dos orientadores de estudo no Pacto Nacional pela Alfabetização na Idade Certa In GUEDES-PINTO, Ana Lúcia; MOMMA-BARDELA, Adriana M.; OLIVEIRA, Samuel Rocha; PREZOTTO, Marissol e MENEZES, Sandra (orgs) Formação continuada de professores alfabetizadores: o PNAIC na UNICAMP (2013-2014).Jundiaí, SP: Paco Editorial, 2016.

EZPELET A, Justa \& ROCKWELL, Elsie. Pesquisa Participante. ( $2^{\text {a }}$ ed.) São Paulo: Autores Associados, 1989. 
FERREIRA, Andrea T. Brito e ALBUQUERQUE, Eliana B. Correia. As rotinas da escola e da sala de aula: referências para a organização do trabalho do professor alfabetizador. In BRASIL, SEB. PNAIC. Caderno 01 Unidade 02, 2012.

FIDELIS, Ana Cláudia e TONIN, Fabiana Bigaton. A leitura deleite no espaço formativo do Programa PNAIC-Unicamp. In GUEDES-PINTO, Ana Lúcia; MOMMABARDELA, Adriana M.; OLIVEIRA, Samuel Rocha; PREZOTTO, Marissol e MENEZES, Sandra (orgs) Formação continuada de professores alfabetizadores: 0 PNAIC na UNICAMP (2013-2014).Jundiaí, SP: Paco Editorial, 2016.

FREITAS, Luiz Carlos de. Ciclos, seriação e avaliação. Confronto de lógicas. São Paulo: Moderna, 2003.

GUEDES-PINTO, Ana Lúcia; SILVA, Leila C. B; FONTANA, Roseli A. C. e TEMPESTA, Maria Cristina S. A organização do tempo pedagógico e o planejamento do ensino. Pró-Letramento, fascículo 03, Brasília: SEB/MEC, 2007

GUEDES-PINTO, Ana L.; MOMMA-BARDELA, Adriana M.; CAMARGO, Giovana Azzi de; BAGNASCO, Daniela G. Pedrazzoli; TASCA, Danieli Sebastiana Oliveira; PROENÇA, Heloísa Helena D. Martins; PAOLETTI, Lígia, FIDELIS, Ana Cláudia e Silva; TONIN, Fabiana Bigaton. Formação, Alfabetização e Letramento: a experiência do Pacto Nacional pela Alfabetização na Idade Certa no contexto do estado de São Paulo. Projeto de Pesquisa CNPq Processo nº408692/2013-8, vigência 11/2013 a 12/2015 - novembro de 2013.

LAJOLO, Marisa; ZILBERMAN, Regina. Das tábuas da lei à tela do computador: a leitura em seus discursos. São Paulo: Ática, 2009.

LEAL, Telma Ferraz. Políticas de alfabetização e currículo. In MACEDO, Maria do Socorro Alencar Nunes e GONTIJO, Cláudia Maria Mendes. (orgs.) Políticas e práticas de alfabetização. Recife: Ed. UFPE, 2017.

LIMA, Ana Lúcia D'Império; CURY, Fernanda Cristina; SERRAO, Luis Felipe Soares; CATELLI JR, Roberto e RIBEIRO, Vera Masagão. INAF 10 anos: panorama dos resultados. In RIBEIRO, Vera Masagão; LIMA, Ana Lúcia D’Império e BATISTA, Antônio Augusto Gomes (orgs) Alfabetismo e Letramento no Brasil: 10 anos do INAF. Belo Horizonte: Autêntica Editora, 2015.

MAGALHÃES, Luciane Manera; ARAUJO, Rita C. B. Freitas; ACHTSCHIN, Simone B. e MELO, Terezinha T. M. Planejamento do ensino: alfabetização e ensino/aprendizagem do componente curricular - Língua Portuguesa. In BRASIL, SEB. PNAIC. Caderno 01 Unidade 02, 2012.

PORTELLI, Alessandro. História Oral como Gênero. In Projeto História.São Paulo: EDUC, n. 22, pp. 9-36, Jun/2001

PRADO, Ricardo; NÓBREGA, Maria José. Apresentação. In: MORAIS, Artur Gomes. Sistema de Escrita Alfabética. São Paulo: Melhoramentos, 2012. 